\title{
Electrochemical Determination of Dopamine on a Glassy Carbon Electrode Modified by Using Nanostructure Ruthenium Oxide Hexacyanoferrate/Ruthenium Hexacyanoferrate Thin Film
}

\author{
Reza Karimi Shervedani and Hossein Ali Alinajafi-Najafabadi \\ Department of Chemistry, University of Isfahan, Isfahan 81746-73441, Iran \\ Correspondence should be addressed to Reza Karimi Shervedani, rkarimi@sci.ui.ac.ir \\ Received 12 February 2011; Revised 5 May 2011; Accepted 5 May 2011 \\ Academic Editor: Kenneth I. Ozoemena
}

Copyright ( $) 2011$ R. K. Shervedani and H. A. Alinajafi-Najafabadi. This is an open access article distributed under the Creative Commons Attribution License, which permits unrestricted use, distribution, and reproduction in any medium, provided the original work is properly cited.

\begin{abstract}
Application of mixed ruthenium oxide hexacyanoferrate/ruthenium hexacyanoferrate glassy carbon electrode for electrochemical determination of dopamine (DA) is described for the first time. The overlapped voltammetric oxidation potentials of ascorbic acid (AA) and DA are separated and shifted to more facile direction, +170 and $+320 \mathrm{mV}$ versus $\mathrm{Ag} / \mathrm{AgCl}$, respectively. Voltammetric response of the electrode toward the DA showed a dynamic calibration curve with two linear parts, from 0.50 to $10.00 \mu \mathrm{M}$ and 25.00 to $550.00 \mu \mathrm{M} \mathrm{DA}$, and a detection limit of $0.195 \mu \mathrm{M}$. The sensitivity $(0.2917 \mu \mathrm{A} / \mu \mathrm{M})$ and detection limit $\left(0.195 \times 10^{-7} \mu \mathrm{MDA}\right)$ of this electrode are 21 times higher and 11.5 times lower than those found in our previous paper. The sensor response of $9.95 \mu \mathrm{MDA}$ was not affected by $5.0 \mathrm{mM}$ of glucose, $4.5 \mathrm{mM}$ of fructose, $0.58 \mathrm{mM}$ of sucrose, $0.28 \mathrm{mM}$ of cystine, $0.25 \mathrm{mM}$ of ascorbic acid, $79.60 \mu \mathrm{M}$ of cysteine, and $49.70 \mu \mathrm{M}$ of uric acid and urea. The fabricated sensor was successfully tested for determination of DA in injection medicine and human blood plasma samples.
\end{abstract}

\section{Introduction}

Dopamine (DA) is a catecholamine neurotransmitter, which is generated in various parts of central and peripheral nervous system that plays an important role in the function of the central nervous, renal, hormonal, and cardiovascular systems. A knowledge of DA level in biological fluids, like blood and urine, is of paramount importance for diagnosis of a number of diseases like Schizophrenia, Parkinsonism, Alzheimer, and HIV infection [1-3]. One of the most important problems in determination of DA is the interference of the active species, like ascorbic acid (AA), accompanying the DA in biological fluids. Therefore, great deal of researches have been carried out to solve this problem, leading to the development of several methods based on chromatography [4], fluorescence [5], spectrophotometery [6], and electrochemistry [7, 8]. Among these methods, the electrochemical techniques are preferred over others due to their simplicity, rapidity, high sensitivity and specificity, reduced power requirements, and ease of fabrication. These techniques are mainly based on electrodes modified by using carbon pastes $[9,10]$, sol-gels [11], polymers [12], and metal oxides [13].

In the previous papers, application of the self-assembled monolayers (SAMs) for determination of DA was reported $[1,14,15]$. In spite of many advantages of SAM-based modified electrodes, like stability and antifouling effects, they suffer from low sensitivity.

Recently, fabrication of the mixed ruthenium oxide hexacyanoferrate/ruthenium hexacyanoferrate (RuOHCF/ RuHCF) thin films on the glassy carbon electrodes (GCE) and testing the electrocatalytic activities of these films towards the DA, epinephrine, norepinephrine [16], peroxiodisulphate $\left(\mathrm{S}_{2} \mathrm{O}_{8}{ }^{2-}\right)$ [17], deoxyguanosine [18], AA [19, 20], and hydrogen peroxide $\left(\mathrm{H}_{2} \mathrm{O}_{2}\right)$ [21] have been reported. Thus, it seems highly promising to modify the surface of the solid electrodes, such as platinum or carbon, using a thin film of RuOHCF/RuHCF and use the electrocatalytic properties of the modified electrode to separate the oxidation potential waves of DA from AA for quantitative determination of DA or AA in the presence of each other. 
However, in spite of potentially interesting characteristics of the RuOHCF/RuHCF thin film modified electrode as a DA electrochemical sensor, detailed sensing behavior of this electrode toward quantitative determination of DA has not been reported yet. Besides, there is a lack of information regarding the characterization of this modified electrode by electrochemical impedance spectroscopy (EIS) and X-ray diffraction (XRD).

The present study is intended to prepare, characterize, and apply the GC/RuOHCF/RuHCF thin film modified electrode as a new sensor for selective determination of DA in the presence of AA. Thus, the sensor is characterized by electrochemical and surface techniques, the experimental conditions are studied, and DA is determined in the best conditions. Finally, the sensor is successfully tested for determination of DA in industrial (injection medicine) and biological (human blood plasma) samples.

\section{Experimental}

2.1. Chemical and Materials. Potassium ferrocyanide, ruthenium(III) chloride, $\mathrm{HCl}, \mathrm{DA}, \mathrm{AA}$, and other materials used in this work were of analytical grade obtained from "Merck and Sigma" and used without further purification. All of the solutions were prepared by double-distilled water. BritonRobinson buffer solutions, in the range of $\mathrm{pH} 2.0$ to 8.0, were prepared using $0.04 \mathrm{M}$ boric acid, $0.04 \mathrm{M}$ acetic acid, and $0.04 \mathrm{M}$ phosphoric acid; and the $\mathrm{pH}$ of the solutions was adjusted with concentrated $\mathrm{NH}_{3}$ solution $(25 \% \mathrm{~W} / \mathrm{W})$. The supporting electrolyte in determination of DA was $0.1 \mathrm{M} \mathrm{NH}_{4} \mathrm{NO}_{3}$. DOPADIC ampoule (Iran Pharmaceutical Development Investment Co., IPDIC, Rasht, I.R. Iran) containing $5 \mathrm{~mL}$ of $200 \mathrm{mg} / \mathrm{mL}$ DA hydrochloride was used as DA source of pharmaceutical sample.

Blood plasma samples were collected from volunteers in Dr. Naser Ekramian's Medical Diagnostic Lab (Isfahan, Najafabad, I.R. Iran). Two $\mathrm{mL}$ of $0.125 \mathrm{M}$ sodium citrate was added to the $18 \mathrm{~mL}$ of fresh blood sample (collected from volunteers, see part 2.1) and mixed. Then, the solution was centrifuged at the $3000 \mathrm{rpm}$. After $5 \mathrm{~min}$, three phases were appeared. The above phase (blood plasma) was separated and used for the next step.

2.2. Electrodes and Instrumentation. A conventional threeelectrode cell, including the modified GC disk $(A=$ $0.0314 \mathrm{~cm}^{2}$, Azar Electrode Co., Urmia, I.R. IRAN) as working electrode, a large surface area Pt plate $\left(99.99 \%, 5 \mathrm{~cm}^{2}\right)$ as auxiliary electrode, and an $\mathrm{Ag} / \mathrm{AgCl}$ (saturated $\mathrm{KCl}$ ) electrode as reference, was used for electrochemical measurements. Electrochemical measurements, including EIS, differential pulse, and cyclic voltammetry methods (DPV and CV), were carried out on Potentiostat/Galvanostat EG\&G273A and Frequency Response Analyzer EG\&G M1025 interfaced with a PC-IV $800 \mathrm{MHz}$ through GPIB-IEEE-NI-488II card and Metrohm 797, respectively. Acquisition of the EIS data was performed using EG\&GPowerSine software. Analysis of the EIS data was performed using ZView2.3 (Scribner Associates, Inc.) on the basis of Macdonald's algorithm (LEVM) using a complex nonlinear least square (CNLS) approximation method [22].

Surface morphology and elemental composition of the electrodeposited film were investigated by scanning electron microscopy (SEM) and energy dispersive X-ray diffraction microanalysis (EDX) (Seron-AIS2100). Crystal spectrum of the film was monitored by XRD analysis (BrukerD8ADVANCE) using $\mathrm{Cu} \mathrm{K} \alpha$ wavelength, $1.5406 \AA$.

2.3. Modification of the Glassy Carbon Electrode. The surface of the GCE is polished by alumina suspension $(5 \mu \mathrm{m})$ on a microcloth polishing pad (Buehler), rinsed with water, and sonicated for $5 \mathrm{~min}$ in distilled water. Deposition of the $\mathrm{RuOHCF} / \mathrm{RuHCF}$ thin film was accomplished by potentiodynamic cycling of the GC electrode between potential limits of -0.5 and $+1.3 \mathrm{~V}$ at $100 \mathrm{mV} / \mathrm{s}$ in supporting electrolyte $\left(0.5 \mathrm{M} \mathrm{NaNO}_{3}+0.05 \mathrm{M} \mathrm{HCl}\right)$ aqueous solution containing $1 \mathrm{mM} \mathrm{K}_{3} \mathrm{Fe}(\mathrm{CN})_{6}$, and $1 \mathrm{mM} \mathrm{RuCl}_{3}$. After film formation, the electrode was thoroughly rinsed with deionized water. The formation of the RuOHCF/RuHCF thin film on the GC surface was verified by immersing the modified electrode in a supporting electrolyte solution containing $0.5 \mathrm{M} \mathrm{NaNO}_{3}+$ $0.05 \mathrm{MHCl}$ and performing repetitive potentiodynamic cycling between preset potential limits according to the literature [18]. The amount of immobilized material on the electrode surface, after potentiodynamic experiments, was controlled by the number of potential cycles, and the number of the active places involving in the heterogeneous charge transfer in this electrocatalytic process $(\Gamma)$ was determined from the charge under the voltammetric peak for the $\mathrm{Ru}(\mathrm{III} / \mathrm{II})$ redox process $\left(Q_{\mathrm{cv}}\right)$ using $\Gamma=Q_{\mathrm{cv}} / n F A$, where $F$ is Faraday constant, $n$ is the number of electrons transferred per molecule of redox active species, and $A$ is the geometric surface area of the electrode [19]. A value was also calculated for $\Gamma$ from EIS measurements based on $\Gamma=4 R T C_{\varphi} / n 2 F 2 A$ according to the literature $[23,24]$, where $T$ is absolute temperature, $R$ is universal gas constant, and $C_{\varphi}$ is pseudocapacitance.

\section{Results and Discussion}

3.1. Construction and Characterization of the Nanostructure RuOHCF/RuHCF Active Thin Film. Formation of RuO$\mathrm{HCF} / \mathrm{RuHCF}$ active thin film monitored by electrochemical methods and surface techniques is described below.

3.1.1. Cyclic Voltammetry. Repetitive cyclic voltammograms recorded during electrodeposition of mixed $\mathrm{RuO}-$ $\mathrm{HCF} / \mathrm{RuHCF}$ thin film from a solution containing $\mathrm{Ru}(\mathrm{III})$, $\left[\mathrm{Fe}(\mathrm{CN})_{6}\right]^{3-}$ at $\mathrm{pH} 1.5$ on the bare GCE (Figure $1(\mathrm{~A})$ ) showed four pairs of redox peaks around (a) -0.1 , (b) 0.6 , (c) 0.9 , and $(\mathrm{d}) 1.1 \mathrm{~V}$. These peaks are attributed to the following electrode processes according to the literature [18]:

(a) $\mathrm{Na}_{4} \mathrm{Ru}^{\mathrm{II}} \mathrm{O}\left[\mathrm{Fe}^{\mathrm{II}}(\mathrm{CN})_{6}\right] \longleftrightarrow \mathrm{Na}_{3} \mathrm{Ru}^{\mathrm{III}} \mathrm{O}\left[\mathrm{Fe}^{\mathrm{II}}(\mathrm{CN})_{6}\right]+$ $\mathrm{Na}^{+}+\mathrm{e}^{-}$

(b) $\mathrm{NaRu}^{\mathrm{III}}\left[\mathrm{Fe}^{\mathrm{II}}(\mathrm{CN})_{6}\right] \longleftrightarrow \mathrm{Ru}^{\mathrm{III}}\left[\mathrm{Fe}^{\mathrm{III}}(\mathrm{CN})_{6}\right]+\mathrm{Na}^{+}+\mathrm{e}^{-}$ 


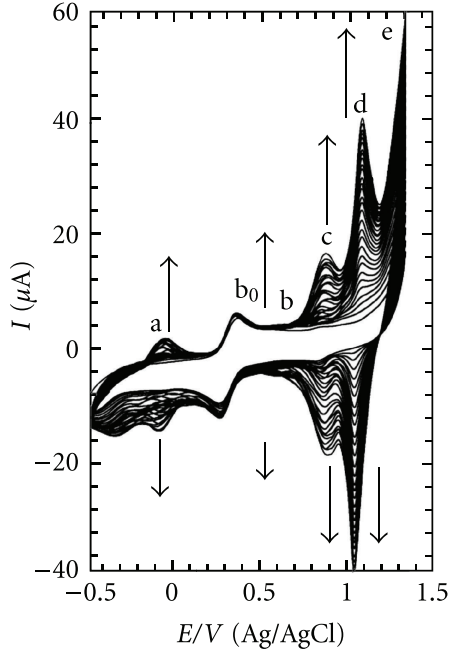

(A)

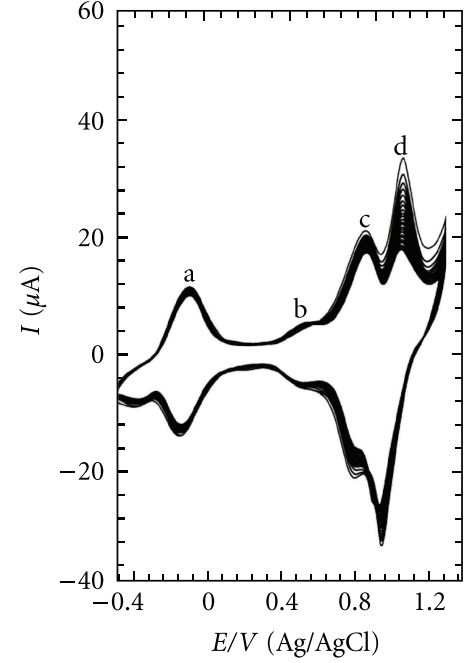

(B)

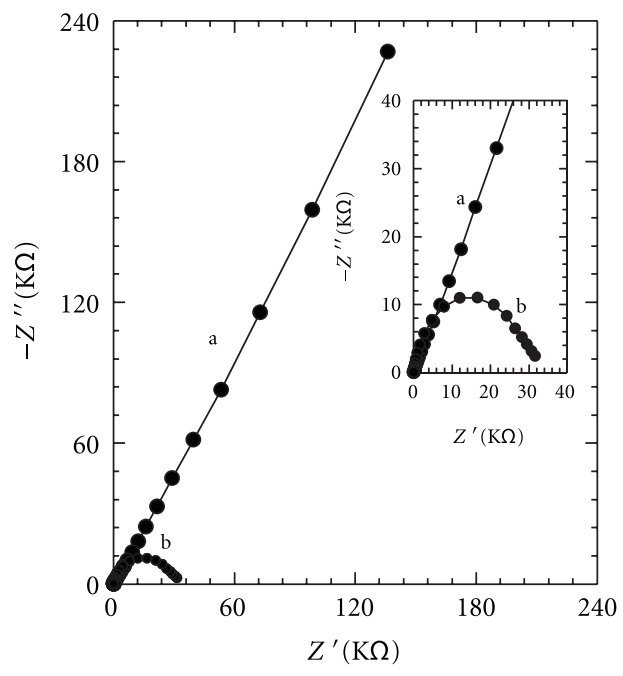

(C)

Figure 1: (A) Repeated cyclic voltammograms recorded on GCE in an aqueous solution containing $0.05 \mathrm{M} \mathrm{HCl}^{2} 0.5 \mathrm{MNaNO}$, $1 \mathrm{mM} \mathrm{K}_{3} \mathrm{FeCN}_{6}$, and $1 \mathrm{mM} \mathrm{RuCl}_{3}$ at $\mathrm{pH} 1.5$ to obtain GC/RuOHCF/RuHCF modified electrode. (B) Consecutive cyclic voltammograms recorded on $\mathrm{GC} / \mathrm{RuOHCF} / \mathrm{RuHCF}$ modified electrode in a solution containing only $0.05 \mathrm{M} \mathrm{HCl}$ and $0.5 \mathrm{M} \mathrm{NaNO}_{3}$. Scan rate: $100 \mathrm{mV} / \mathrm{s}$. (C) EIS complex plane plots obtained on (a) the bare GCE and (b) GC/RuOHCF/RuHCF modified electrode in a solution containing only $0.5 \mathrm{M} \mathrm{NaNO}_{3}$ at $\mathrm{pH} 1.5, E_{\mathrm{DC}}=+0.5$ versus $\mathrm{Ag} / \mathrm{AgCl}, E_{\mathrm{ac}}=15 \mathrm{mV}$, and frequency range: $10 \mathrm{kHz}$ to $10 \mathrm{mHz}$.

(c) $\mathrm{Na}_{3} \mathrm{Ru}^{\mathrm{III}} \mathrm{O}\left[\mathrm{Fe}^{\mathrm{II}}(\mathrm{CN})_{6}\right] \longleftrightarrow \mathrm{Na}_{2} \mathrm{Ru}^{\mathrm{III}} \mathrm{O}\left[\mathrm{Fe}^{\mathrm{III}}(\mathrm{CN})_{6}\right]+$ $\mathrm{Na}^{+}+\mathrm{e}^{-}$

(d) $\mathrm{Na}_{2} \mathrm{Ru}^{\mathrm{III}} \mathrm{O}\left[\mathrm{Fe}^{\mathrm{III}}(\mathrm{CN})_{6}\right] \longleftrightarrow \mathrm{NaRu}^{\mathrm{IV}} \mathrm{O}\left[\mathrm{Fe}^{\mathrm{III}}(\mathrm{CN})_{6}\right]+$ $\mathrm{Na}^{+}+\mathrm{e}^{-}$

Wave (e) is attributed to the background. A comparison between these results (Figure 1(A)), and the repetitive cyclic voltammograms obtained on the modified electrode in a solution containing only supporting electrolyte solution at $\mathrm{pH} 1.5$ (Figure 1(B)), indicates an additional reversible wave $\left(b_{0}\right)$ around $+0.32 \mathrm{~V}$ (Figure $1(\mathrm{~A})$ ) that could be attributed to the presence of $\mathrm{K}_{3} \mathrm{Fe}(\mathrm{CN})_{6}$ in deposit solution (i.e., the reaction of $\left.\left[\mathrm{Fe}(\mathrm{CN})_{6}\right]^{4-} \longleftrightarrow\left[\mathrm{Fe}(\mathrm{CN})_{6}\right]^{3-}+\mathrm{e}^{-}\right)$. A comparison between the $\mathrm{CV}$ recorded on the bare GCE in a solution containing $0.05 \mathrm{M} \mathrm{HCl}, 0.5 \mathrm{M} \mathrm{NaNO}_{3}$, and $1 \mathrm{mM}$ $\mathrm{K}_{3} \mathrm{FeCN}_{6}$ and the background recorded in these conditions but in the absence of $\mathrm{K}_{3} \mathrm{FeCN}_{6}$ supported this ascription (data not shown). These behaviors demonstrate formation of RuOHCF/RuHCF thin film on GCE.

3.1.2. Electrochemical Impedance Spectroscopy. EIS is a powerful, nondestructive, and informative technique that has played an essential role in kinetic characterization and diagnosis of the events occurring at the different types of electrode/solution interfaces in a wide range of applied DC potentials [22-28]. EIS studies of RuOHCF/RuHCF thin film have not been reported till now.

In this step of the work, EIS measurements are performed in different conditions (including $\mathrm{pH}, \mathrm{AC}$, and DC potentials, and external redox probes) to trace and support formation of $\mathrm{RuOHCF} / \mathrm{RuHCF}$ thin film on the GC electrode. After testing the conditions, a sensitive and reproducible behavior was found by using $15 \mathrm{mV}$ peaktopeak
AC potential superimposed on $+0.5 \mathrm{~V}$ DC potential, in the frequency range of $10 \mathrm{kHz}$ to $10 \mathrm{mHz}$, at $\mathrm{pH} 1.5$ based on the confined redox reaction of RuHCF (i.e., in the absence of external probe). Then, the impedances recorded in these conditions were analyzed to find the kinetics of the modified electrode.

Typical EIS complex plane plots $\left(-Z_{\text {im }}\right.$ versus $\left.Z_{\mathrm{re}}\right)$ obtained on the bare GC and GC/RuOHCF/RuHCF thin film electrodes are presented in Figure 1(C). The bare GCE in background electrolyte exhibits almost a straight line (curve a), which is characteristic of a pure capacitive effect in series with a pure resistant $[22,25-31]$. However, the deposited film shows a faradic charge transfer behavior, which is reflected by the appearance of the semicircle part on the spectrum (curve b). Since the experiments have been performed in the background electrolyte solution in the absence of any external redox probe, this behavior is attributed to the confined faradaic redox reaction on the $\mathrm{GC} / \mathrm{RuOHCF} / \mathrm{RuHCF}$ electrode surface.

A detailed theoretical study regarding EIS of the electroactive thin films has already been reported [23, 24, 32-36]. Accordingly, we assumed (i) a pseudocapacitance $\left(C_{\varphi}\right)$ and (ii) a double-layer capacitance $\left(C_{\mathrm{dl}}\right)$ effect, which are originating, respectively, from the (i) fast reversible faradaic reaction of the confined redox centers occurring on the $\mathrm{GC} / \mathrm{RuOHCF} / \mathrm{RuHCF}$ electrode surface and (ii) charge separation at the electrode/electrolyte interface. Then, the contribution of these elements to the total impedance of the electrode is estimated using appropriate equivalent circuit models.

Several equivalent circuit models are applied, EIS data are approximated, and finally, more appropriate models, considering criteria of the fit [22] like the number of 
model parameters, their physical meaning, errors of the fit, and overall quality of the fit $\left(\chi^{2}\right)$, are selected (Figure 2, models (a) and (b) for the bare and modified electrodes, respectively, and the electrodes kinetic parameters such as solution resistance $\left(R_{s}\right)$, charge transfer resistance $\left(R_{\mathrm{ct}}\right), C_{\varphi}$, and $C_{\mathrm{dl}}$, are extracted (Table 1).

The $C_{\varphi}$, which is an indicative of the active sites formed on the electrode surface by modification process, can help to estimate $\Gamma$, where $\Gamma=4 R T C_{\varphi} / n^{2} F^{2} A[23,24]$. Accordingly, a value of $8.02 \times 10^{-9} \mathrm{~mole} / \mathrm{cm}^{2}$ is obtained for $\Gamma$ via the EIS measurements. This value is in good agreement with that observed by $\mathrm{CV}, \Gamma=Q_{\mathrm{cv}} / n F A=$ $8.4 \times 10^{-9} \mathrm{~mole} / \mathrm{cm}^{2}$ (Figure $1(\mathrm{~B})$, peak (a)) with $\Delta \Gamma \%=$ 4.6, where $\Delta \Gamma \%=\left[2\left(\Gamma_{\mathrm{cv}}-\Gamma_{\mathrm{EIS}}\right) /\left(\Gamma_{\mathrm{CV}}+\Gamma_{\mathrm{EIS}}\right)\right] \times 100$. These results support the formation of active $\mathrm{RuOHCF} / \mathrm{RuHCF}$ thin film. The electrocatalytic activity of this thin film modified electrode towards the substrate, that is, DA, is subsequently studied in this work (Section 3.2).

3.1.3. Surface Morphology. Typical SEM micrographs obtained on the surface of the bare GC and GC/RuOHCF/ RuHCF electrodes are presented in Figures 3(a) and 3(b), respectively. Particles with diameter below $100 \mathrm{~nm}$ are observed in the SEM micrograph (Figure 3(b)), indicating a nanostructure for the RuOHCF/RuHCF deposited thin film on the GCE.

A typical EDX spectrum obtained from surface of the modified electrode is also presented in Figure 3(c). The presence of the $\mathrm{Ru}, \mathrm{Fe}, \mathrm{Na}, \mathrm{O}$, and $\mathrm{C}$ elements is shown in the spectrum. The sharp peak of carbon at $(0.3 \mathrm{keV})$ in spectrum is related to the GC base. This information also supports formation of RuOHCF/RuHCF thin film on the surface of GCE.

The XRD spectrum of the modified surface is displayed in Figure 3(d). This spectrum includes a sharp peak and several small ones, indicating a crystalline structure for $\mathrm{RuOHCF} / \mathrm{RuHCF}$ film. Up to our knowledge, there is no XRD data about structure of RuOHCF/RuHCF film in literature. A systematic investigation of the structure and the phase or phases possibly existing in this compound is not the purpose of this work. However, Scherrer's equation [37] is used to estimate the grain size, and values of 27.8, 21.5, 22.5, and $26.5 \mathrm{~nm}$ are obtained for $2 \theta$ of $18.224^{\circ}, 31.657^{\circ}, 37^{\circ}$, and $41.5^{\circ}$, respectively. The average grain size is about $24.8 \mathrm{~nm}$, indicating a nanostructure for RuOHCF/RuHCF film.

\subsection{Electrocatalytic Activities of $\mathrm{GC} / \mathrm{RuOHCF} / \mathrm{RuHCF}$ Elec- trode towards the Oxidation of DA}

3.2.1. Cyclic Voltammetry. The cyclic voltammogram obtained on the bare GCE (Figure 4, curve (a1)) shows sluggish electron transfer kinetics for redox reaction of DA $\left(E_{\mathrm{pa}}=+465 \mathrm{mV}\right.$ and $\left.E_{\mathrm{pc}}=+162 \mathrm{mV}\right)$ with a large peak separation $\left(\Delta E_{\mathrm{p}} \cong 300 \mathrm{mV}\right)$, which can be related to nature of DA redox reaction on the unmodified electrode as well as fouling of the bare GCE surface by DA and its oxidation products [38]. However, the anodic and cathodic peak potentials are shifted to more facile direction $\left(E_{\mathrm{pa}}=+320 \mathrm{mV}\right.$

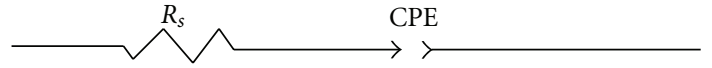

(a)

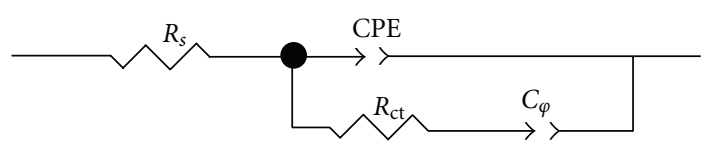

(b)

FIgURE 2: Equivalent circuits used for approximation of the EIS data. (a) The bare GC and (b) GC/RuOHCF/RuHCF electrodes in the absence of external probe.

and $E_{\mathrm{pc}}=+264 \mathrm{mV}$ ) on $\mathrm{GC} / \mathrm{RuOHCF} / \mathrm{RuHCF}$ electrode, indicating an electrocatalytic effect for DA oxidation. Also, a comparison between anodic peak currents indicates that the oxidation peak current of DA is increased by a factor of 8 from the bare to the modified GCE (Figures 4(a1) and $4(\mathrm{a} 2))$. An increase in the current or a shift in the reaction potential to more facile direction for an electrochemical reaction observed on a modified electrode surface is so called the electrocatalytic effect of the modifier. Interestingly, here, both effects are observed for GC/RuOHCF/RuHCF thin film towards the oxidation of DA.

Variations of the oxidation peak current of DA $\left(I_{\mathrm{p}, \mathrm{a}}\right)$ as a function of the potential scan rate $(v)$ depicted a linear behavior in the range of 10 to $120 \mathrm{mV}$ (data not shown) $\left[I_{\mathrm{p}, \mathrm{a}}(A)=1 \times 10^{-5} \mathrm{v}\left(\mathrm{V} \mathrm{s}^{-1}\right)+4 \times 10^{-7}, r^{2}=0.999\right]$, indicating that the charge transfer rate at the GC/RuOHCF/RuHCF electrode surface is controlled by the redox reaction of DA adsorbed on the surface. This behavior is used subsequently in this work to develop a method for direct quantitative determination of DA based on anodic adsorptive striping voltammetry (see Section 3.3).

3.2.2. Electrochemical Impedance Spectroscopy. Oxidation of $\mathrm{DA}$ at the bare and GC/RuOHCF/RuHCF electrodes is also studied by the EIS. The complex plane plots obtained for $1 \mathrm{mMDA}$ at the bare (curve a) and modified (curve b) electrodes are presented in Figure 4(B). The data are approximated, based on the argument presented in Section 3.1.2, using appropriate equivalent circuits (Figures 5(a) and 5(b)) for the bare $\mathrm{GC}$ and the $\mathrm{GC} / \mathrm{RuOHCF} / \mathrm{RuHCF}$ electrodes, respectively). The values estimated for the model parameters are presented in Table 2. The slow reaction of DA at the unmodified electrode causes only a semicircle in complex plane plot with a negligible effect of Warburg impedance (Figure 4(B)). The formation of RuOHCF/RuHCF thin film on GCE has led to a decrease in $R_{\mathrm{ct}}$ by a factor of 29 . This behavior can be attributed to the adsorption of DA on $\mathrm{GC} / \mathrm{RuOHCF} / \mathrm{RuHCF}$ thin film, which is revealed by a $C_{\varphi}$ of $26.7 \mu \mathrm{F}$. Since the redox reaction of adsorbed DA is accompanied by diffusion of proton ion $\left(\mathrm{H}^{+}\right)$, the low-frequency range line in the impedance spectrum is attributed to the Warburg impedances associated with proton diffusion at the film/electrolyte interface $[39,40]$ (see Table S1 in Supplementary Material available online at doi: 10.4061/2011/603135). 
TABLE 1: Kinetic parameters extracted using EIS data obtained on the bare GC and GC/RuOHCF/RuHCF electrodes in $0.5 \mathrm{M}$ NaNO3 at pH 1.5 , in the absence of any external probe, $A=0.0314 \mathrm{~cm} 2, E_{D C}=+0.5$.

\begin{tabular}{lccccc}
\hline Electrode & $R_{\mathrm{s}}(\Omega)$ & $R_{\mathrm{ct}}(\Omega)$ & $Q_{\varphi}(\mu \mathrm{F})$ & $Q_{\mathrm{dll}}(\mu \mathrm{F})$ & $n$ \\
\hline Bare GC & $21.03 \pm 3.00$ & - & - & $19.40 \pm 0.20$ & 0.70 \\
GC/RuOHCF/RuHCF & $50.75 \pm 0.35$ & $(3.01 \pm 0.23) \times 10^{4}$ & $(2.30 \pm 0.10) \times 10^{3}$ & $12.60 \pm 0.30$ & 0.80 \\
\hline
\end{tabular}

$\chi^{2}=6.98 \times 10^{-3}$.

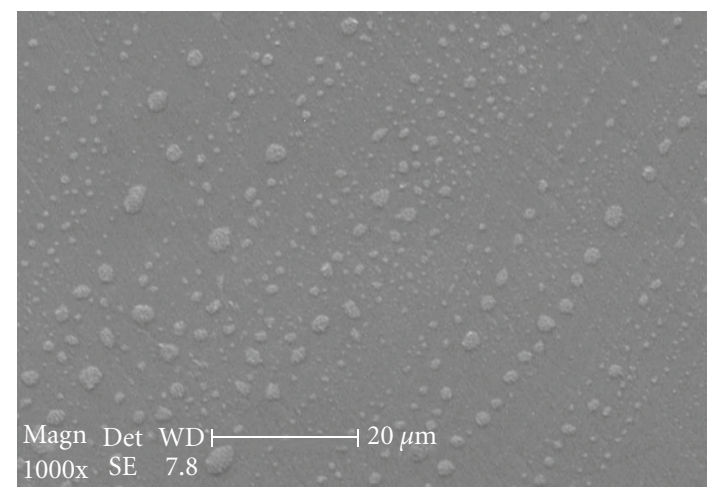

(a)

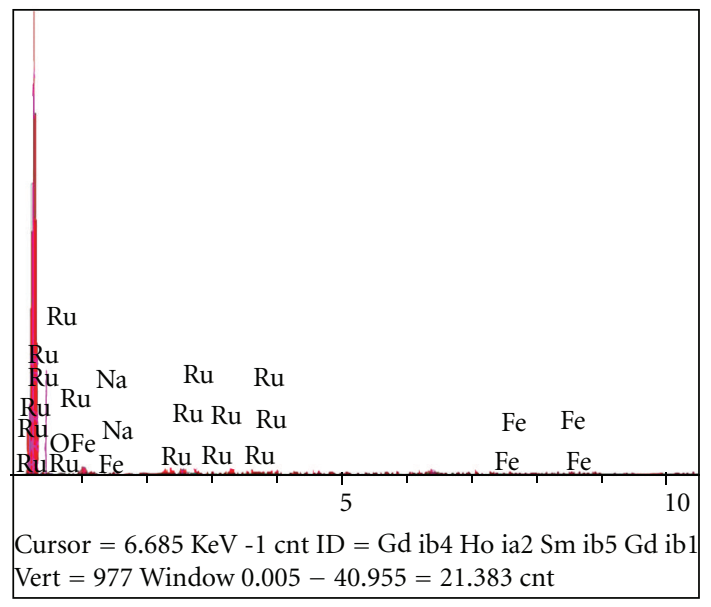

(c)

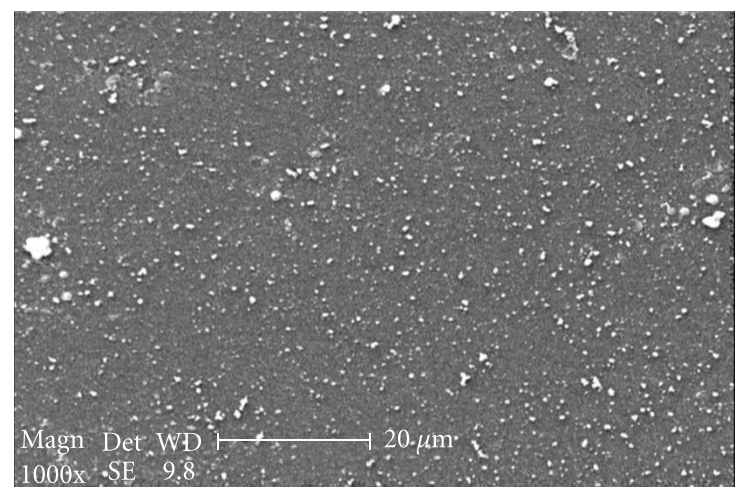

(b)

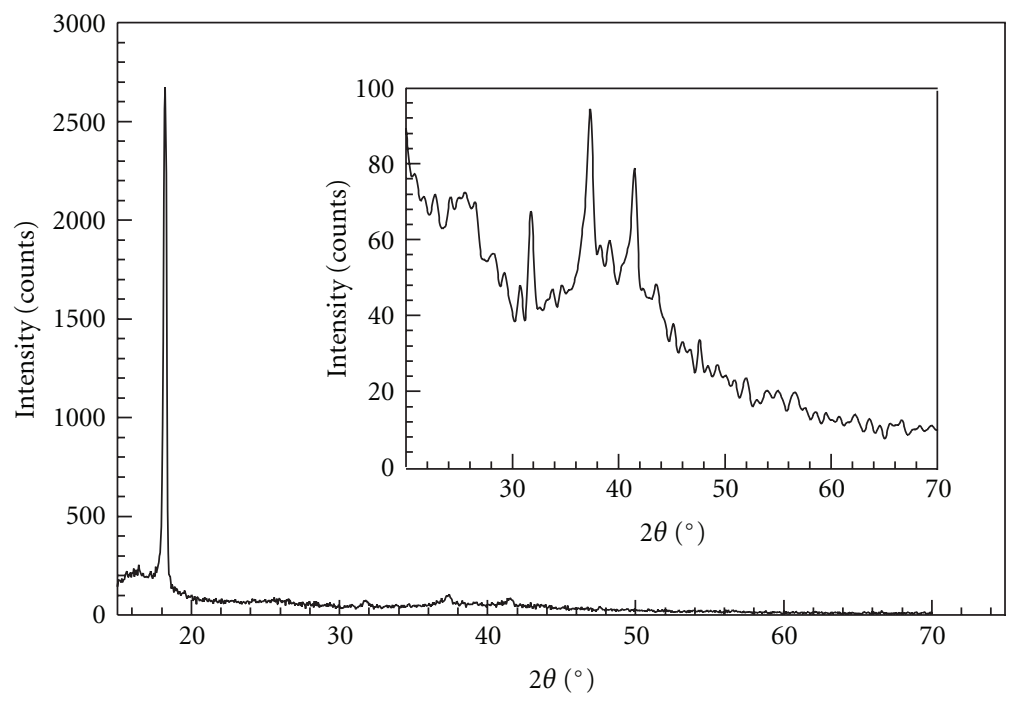

(d)

FIGURE 3: SEM microphotographs obtained on (a) the bare GC and (b) GC/RuOHCF/RuHCF modified electrodes. (c) EDX microanalysis spectrum and (d) XRD spectra of GC/RuOHCF/RuHCF modified electrode obtained using Cu $\mathrm{K}_{\alpha} 1.5406 \AA$.

So, $I_{\mathrm{p}}$ of voltammetry and also $1 / R_{\mathrm{ct}}$ of EIS measurements are found to be proportional to the DA concentration in solution phase [DA]. As a conclusion, an adsorption/oxidation mechanism may be assumed for DA via $\mathrm{RuOHCF} / \mathrm{RuHCF}$ thin film active sites, in which adsorption step is relatively fast, under equilibrium, and proportional to the DA concentration in solution phase. This object is studied in Section 3.3.

3.2.3. Effect of Operational Parameters. Effect of $\mathrm{pH}$, supporting electrolyte, and ionic strength of the working solution on the electrocatalytic oxidation of the DA at
GC/RuOHCF/RuHCF are studied by monitoring the anodic stripping differential pulse voltammetry peak current $\left(I_{\mathrm{p}, \mathrm{a}}\right)$ of adsorbed DA in a BrittonRobinson buffer solution containing a fixed concentration of DA $(20 \mu \mathrm{MDA})$, and varying each one of the parameters. Data are not shown to save the space. The $I_{\mathrm{p}, \mathrm{a}}$ of $\mathrm{DA}$ showed a maximum value around $\mathrm{pH} 5.0$ in BrittonRobinson buffer solution containing $0.10 \mathrm{M} \mathrm{NH}_{4} \mathrm{NO}_{3}$ as an electrolyte. Accumulation potential is examined in the range of +150 to $-500 \mathrm{mV}$ at a constant time (60 s) and $\mathrm{pH}(5.0)$ in BrittonRobinson buffer solution containing $0.10 \mathrm{M} \mathrm{NH}_{4} \mathrm{NO}_{3}$ and $20 \mu \mathrm{MDA}$. A maximum of $I_{\mathrm{p}, \mathrm{a}}$ was found around $-500 \mathrm{mV}$ versus $\mathrm{Ag} / \mathrm{AgCl}$ and used as optimized potential in the next step 

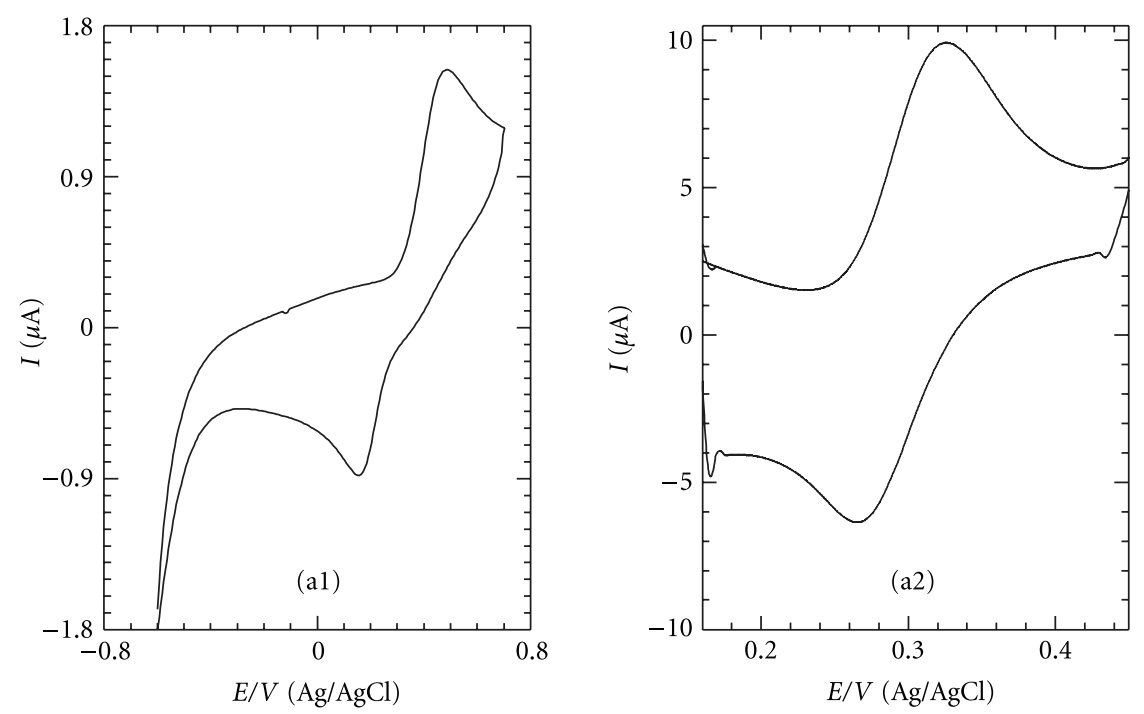

(A)

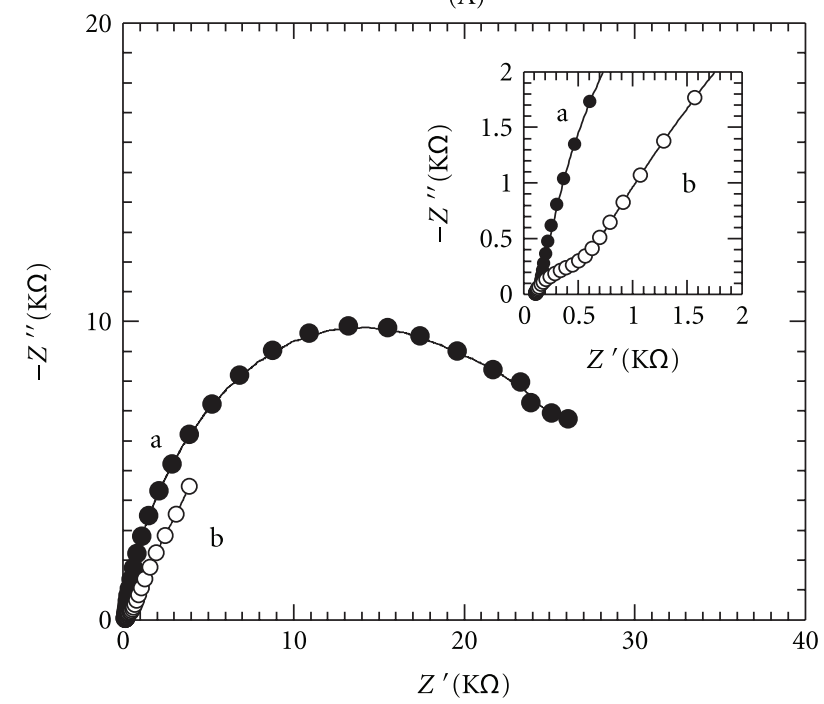

(B)

FIgure 4: (A) Cyclic voltammograms obtained on the bare GC (a1) and GC/RuOHCF/RuHCF modified (a2) electrodes in the presence of $0.2 \mathrm{mM} \mathrm{DA}$ at pH 5. Scan rate $100 \mathrm{mV} / \mathrm{s}$. (B) Complex plane plots obtained in $0.1 \mathrm{M} \mathrm{NH}_{4} \mathrm{NO}_{3}$ in the presence of $1 \mathrm{mM} \mathrm{DA}$ at pH 5 on (a) the bare GC, and (b) GC/RuOHCF/RuHCF modified electrodes. $E_{\mathrm{DC}}=+0.260 \mathrm{~V}$ versus $\mathrm{Ag} / \mathrm{AgCl}, E_{\mathrm{ac}}=15 \mathrm{mV}$, and frequency range: $10 \mathrm{kHz}$ to $10 \mathrm{mHz}$.

TABLE 2: Kinetic parameters extracted using the EIS data obtained on the bare GCE and modified GC/RuOHCF/RuHCF electrodes in $0.1 \mathrm{M} \mathrm{NH}_{4} \mathrm{NO}_{3}$ at pH 5 in the presence of $1 \mathrm{mM} \mathrm{DA}, A=0.0314 \mathrm{~cm}^{2}, E_{D C}=+0.260 \mathrm{~V}$.

\begin{tabular}{|c|c|c|c|c|c|}
\hline Electrode & $R_{s}(\Omega)$ & $R_{\mathrm{ct}}(\Omega)$ & $Q_{\varphi}(\mu \mathrm{F})$ & $Q_{\mathrm{dl}}(\mu \mathrm{F})$ & $n$ \\
\hline Bare GC & $62.90 \pm 13.00$ & $(2.54 \pm 0.45) \times 10^{4}$ & - & $2.20 \pm 0.01$ & 0.80 \\
\hline GC/RuOHCF/RuHCF & $109.10 \pm 0.50$ & $874.90 \pm 92.30$ & $98.87 \pm 19.47$ & $17.94 \pm 6.06$ & 0.80 \\
\hline
\end{tabular}

$\chi^{2}=8.67 \times 10^{-5}$.

to study the accumulation time. A plot of $I_{\mathrm{p}, \mathrm{a}}$ of DA versus accumulation time showed that after $30 \mathrm{~s}$, the oxidation peak current was almost invariant. So, $30 \mathrm{~s}$ is selected as optimum time. Finally, the instrumental parameters were optimized. Accordingly, the best conditions for determination of DA by DPV are summarized as follows: $\mathrm{pH}$ (5.0), supporting electrolyte and ionic strength (BritonRobison buffer, containing $\left.0.1 \mathrm{M} \mathrm{NH}_{4} \mathrm{NO}_{3}\right)$, accumulation potential $(-0.5 \mathrm{~V})$, accumulation time $(30 \mathrm{~s})$, scan rate $(14 \mathrm{mV} / \mathrm{s})$, and pulse amplitude $(65 \mathrm{mV})$. After recording each DPV, the electrode surface was recovered by keeping the electrode at $+0.7 \mathrm{~V}$ for $30 \mathrm{~s}$ in blank solution. 


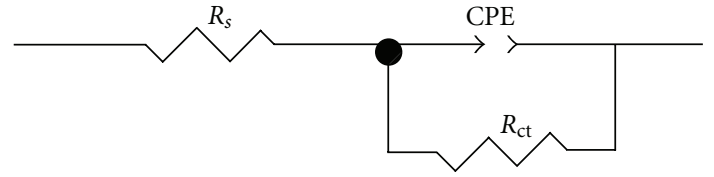

(a)

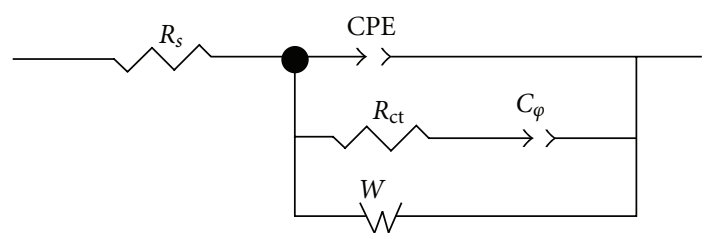

(b)

FIGURE 5: Equivalent circuits used for approximation of the EIS data: (a) the bare GC and (b) GC/RuOHCF/RuHCF electrodes in the presence of DA (external probe). Warburg element considers the possible contribution of DA in the solution phase at very low frequency. The double-layer capacitance is replaced by constant phase element CPE.

\subsection{Analytical Application for Determination of $D A$}

3.3.1. Merits of the Method. Under the optimum conditions, the calibration curve is constructed by systematically increasing the concentration of $\mathrm{DA}$, from $5.0 \times 10^{-7}$ to $5.50 \times 10^{-4} \mathrm{M}$, in the test solution and monitoring the response of $\mathrm{GC} / \mathrm{RuOHCF} / \mathrm{RuHCF}$ electrode by anodic stripping of DA (Figure 6). The peak currents are extracted and plotted versus concentration. A dynamic calibration curve with two linear ranges, from $5.0 \times 10^{-7}$ to $1.0 \times$ $10^{-5}$ and $25.0 \times 10^{-5}$ to $5.50 \times 10^{-4} \mathrm{MDA}$, is observed as $\left[I_{\mathrm{p}}(A)=0.2917( \pm 0.0023)[\mathrm{DA}]-0.100 \times 10^{-6}( \pm 0.001 \times\right.$ $\left.\left.10^{-6}\right), r^{2}=0.999\right]$ and $\left[I_{\mathrm{p}}(A)=0.061( \pm 0.004)[\mathrm{DA}]+\right.$ $\left.\left.5.000 \times 10^{-6}\left( \pm 0.001 \times 10^{-6}\right), r^{2}=0.991\right)\right]$, respectively (Figure 6, insets). The detection limit of this electrode, calculated from the standard deviation $(S)$ of the background (for signal equals $3 S$, where $S=1.897 \times 10^{-8}$ A for 8 measurements [3]), is $1.95 \times 10^{-7} \mathrm{MDA}$, and the relative standard deviation (RSD) for 4 measurements at $9.95 \times 10^{-6} \mathrm{M} \mathrm{DA}$ is $2.36 \%$. These results indicate that the GC/RuOHCF/RuHCF electrode is a sensitive sensor for detection of DA at low concentrations. The sensitivity $(0.2917 \mu \mathrm{A} / \mu \mathrm{M})$ and detection limit $\left(1.95 \times 10^{-7} \mathrm{MDA}\right)$ of this electrode are, respectively, 21 times higher and 11.5 times lower than those found in our previous report [15]. In addition, these results indicate that the sensitivity and detection limit of this electrode are, respectively, 1.6 time higher and 2.1 times lower than those found on thick film chemically modified electrodes in the best conditions (see Supporting Information, Table S2, row 2).

3.3.2. Effect of Interferences on Determination of DA. The main interference in determination of DA in biological fluids is AA. On the bare electrode, AA is oxidized almost at the same potential as DA, in a very similar mechanism. Therefore, overlapped voltammetric responses for the oxidation of DA and AA are usually observed on the bare electrodes. Also,

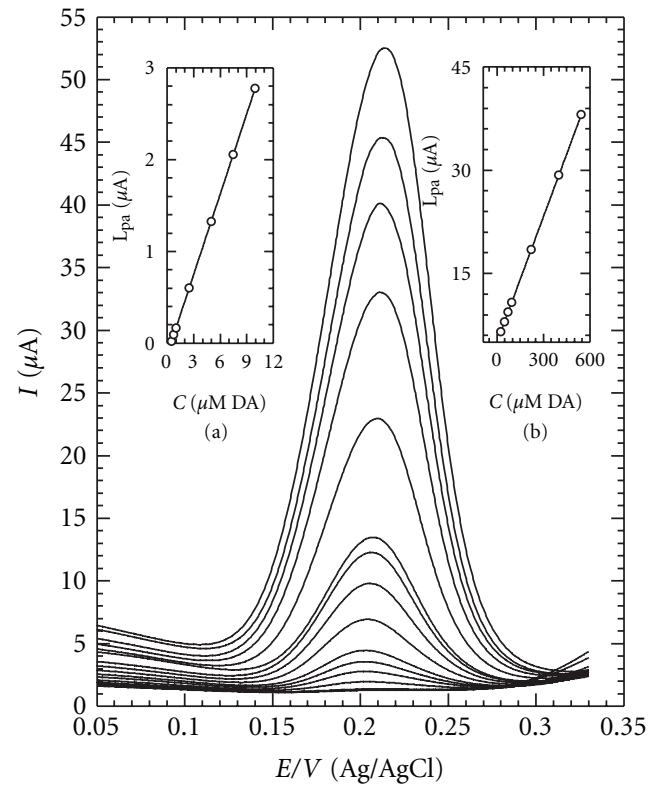

Figure 6: Differential pulse voltammograms recorded in the presence of different concentration of DA in $0.1 \mathrm{M} \mathrm{NH}_{4} \mathrm{NO}_{3}$ at $\mathrm{pH}$ 5 . The insets show the two linear range calibration curves extracted from the voltammograms; (a) lower range and (b) upper range. See the text for details.

large overpotentials for such oxidations and fouling of the electrode surface by the electrochemical oxidation products of DA and AA impose difficulties in the voltammetric determination of DA [41]. By using this modified electrode, $\mathrm{GC} / \mathrm{RuOHCF} / \mathrm{RuHCF}$, the overlapped oxidation potentials of AA and DA $(+512 \mathrm{mV})$ on the bare GCE are separated by $150 \mathrm{mV}$ and shifted to more facile direction (i.e., to less positive values), +170 and $+320 \mathrm{mV}$ versus $\mathrm{Ag} / \mathrm{AgCl}$, respectively (Figure 7). This behavior allows elimination of the interferences of several of biological species, in particular, the effect of AA.

Overall shift in oxidation potentials of AA and DA is attributed to the electrocatalytic activity of the film toward these species. Separation of AA and DA oxidation peak potentials could be due to different mechanisms that they follow in this process. While AA is not adsorbed on the electrode, DA is expected to follow an adsorptionoxidation mechanism. Thus, oxidation potential of AA is shifted from $500 \mathrm{mV}$ to $+170 \mathrm{mV}$ versus $\mathrm{Ag} / \mathrm{AgCl}$ in comparison with that of DA, which is shifted to $+320 \mathrm{mV}$ versus $\mathrm{Ag} / \mathrm{AgC}$.

Thus, we examined possible interferences in the determination of DA under the optimum experimental conditions. For this purpose, the $9.95 \mu \mathrm{M}$ DA samples were taken, different amounts of each interferent were added, and their voltammograms were recorded. The interference effect is defined as the concentration of an interfering species that can change the electrode response towards the analyte by a value more than that predicted by $t$-test. The results show that the peak current of $9.95 \mu \mathrm{M}$ DA in the confidence intervals, determined at $95 \%$ for $n=8$, is not affected by $5.0 \mathrm{mMof}$ glucose, $4.5 \mathrm{mM}$ of fructose, $0.58 \mathrm{mM}$ of sucrose, $0.28 \mathrm{mM}$ of 


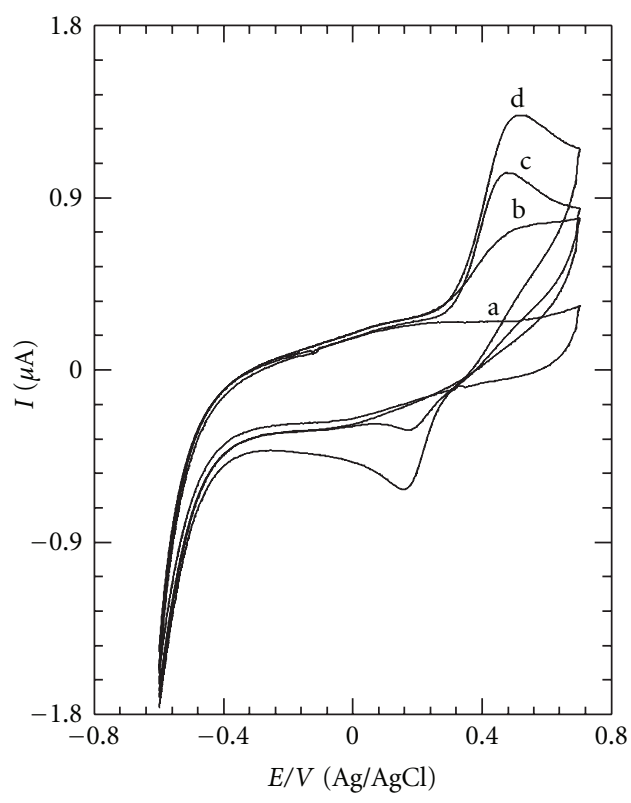

(a) Blank

(b) $100 \mu \mathrm{M} \mathrm{AA}$

(c) $120 \mu \mathrm{M} \mathrm{DA}$

(d) $100 \mu \mathrm{M} \mathrm{DA}$ and $100 \mu \mathrm{M}$ AA

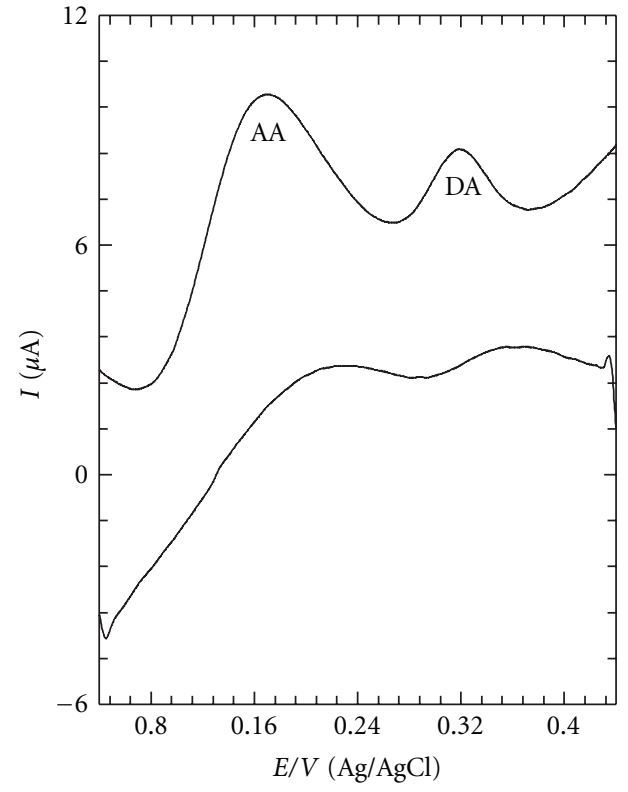

(B)

Figure 7: Cyclic voltammograms obtained on (A) the bare GCE in different solutions, blank (curve a), $100 \mu \mathrm{M}$ AA (curve b), $120 \mu \mathrm{M}$ DA (curve c), and in a mixture solution of $100 \mu \mathrm{M}$ AA and $100 \mu \mathrm{M} \mathrm{DA}$ (curve d) and (B) GC/RuOHCF/RuHCF electrode in a mixture solution of $1.5 \mathrm{mM} \mathrm{AA}$ and $50 \mu \mathrm{M}$ DA. pH 5, scan rate: $100 \mathrm{mV} / \mathrm{s}$.

cystine, $0.25 \mathrm{mM}$ of ascorbic acid, $79.6 \mu \mathrm{M}$ of cysteine, and $49.7 \mu \mathrm{M}$ of uric acid or urea. Further studies indicated that effect of interferences did not depend on DA concentration. Therefore, the standard addition methods can be efficiently used for analysis of the DA in real samples.

\subsection{Application for Analysis of the Real Samples}

3.4.1. Determination of Dopamine in Injection Medicines. Four pharmaceutical samples were prepared, and their DA concentration was adjusted by dilution of DOPADIC ampoule contents $(5 \mathrm{~mL}$ of $200 \mathrm{mg} / \mathrm{mL}$ DA hydrochloride injection solution) in buffer solution, $\mathrm{pH}$ 5.0. Then, each sample was transferred to electrochemical cell for determination of its DA content (Table 3). The results show that the proposed method can be effectively used for the determination of DA in industrial (injection medicine) samples.

3.4.2. Determination of Dopamine in Human Blood Plasma Samples. Five portions of $1.0 \mathrm{~mL}$ of this phase were used for quantitative analysis by electrochemical methods. Because the amount of DA in blood sample was below the detection limit of the method $\left(1.95 \times 10^{-7} \mathrm{MDA}\right)$, a constant volume of the $2 \mathrm{mM}$ DA (considered as unknown, $V_{x}$ ) was spiked into a number of blood plasma samples and, then, diluted in volumetric vessels with buffer solution, $\mathrm{pH} 5$, so that, each one of the samples contained $7.5 \times 10^{-7} \mathrm{M} \mathrm{DA}$ (above
TABLE 3: Results of the recovery tests obtained for determination of DA in real sample (DOPADIC ampoule) after dilution to different concentrations. Results are average of four measurements on each sample.

\begin{tabular}{lccc}
\hline $\begin{array}{l}C_{\mathrm{DA}} / \mu \mathrm{M} \\
\text { (Expected) }\end{array}$ & $\begin{array}{c}C_{\mathrm{DA}} / \mu \mathrm{M} \\
\text { (Recovered) }\end{array}$ & Recovery \% & $\begin{array}{c}\% \text { RSD } \\
\text { (Recovered) }\end{array}$ \\
\hline 4.98 & 5.03 & 101.03 & 1.50 \\
7.47 & 7.37 & 98.70 & 1.30 \\
9.95 & 10.00 & 100.50 & 2.36 \\
66.60 & 67.50 & 101.35 & 3.89 \\
\hline
\end{tabular}

the detection limit). Then, these solutions were applied for determination of DA by standard addition method using different volumes of $2 \mathrm{mM} \mathrm{DA}$ (considered as $V_{s}$ ), similar to the method reported in literature for adenosine [2]. A linear relation is observed (Figure 8) for $I_{\mathrm{p}, \mathrm{a}}$ versus DA concentration $\left(V_{s}\right)$ as $\left[I_{\mathrm{p}}(\mu \mathrm{A})=10.0( \pm 0.7) V_{s}+0.0040( \pm 0.0009)\right.$, $\left.r^{2}=9913\right]$. Using this equation, one can find the concentration of spiked solution, $C_{x}$. Accordingly, the recovery values are found to be $106.6 \%$ for the first recovery and $98.7 \%$ and $102.9 \%$ for the subsequent tests.

\section{Conclusions}

Layers of RuOHCF/RuHCF were successfully electrodeposited onto the surface of GCE and characterized by 


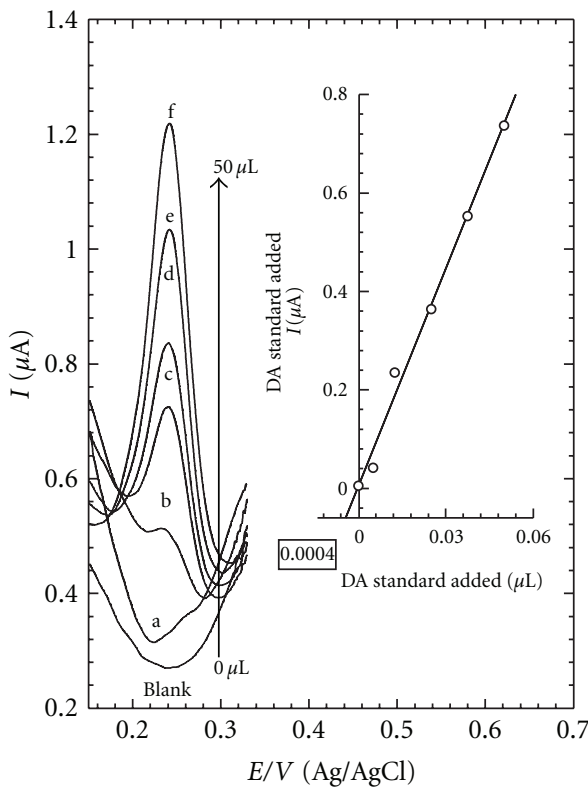

Figure 8: Differential pulse voltammograms obtained on GC/RuOHCF/RuHCF electrode. Solutions prepared by standard addition into the blood plasma as follows: (a) 0.00, (b) 5.0, (c) 12.5, (d) 25.0 , (e) 37.5 , and (f) $50.0 \mu \mathrm{L}$ of $2 \mathrm{mM} \mathrm{DA}$ solution. Inset shows calibration curve obtained from variations of the stripping peak current as a function of DA concentration (see the text for details).

using surface techniques and electrochemical methods such as SEM, EDX, XRD, EIS, DPV, and CV. The $\mathrm{GC} / \mathrm{RuOHCF} / \mathrm{RuHCF}$ electrode was applied for quantitative detection of DA at $\mathrm{pH} 5.0$ for the first time. The electrode exhibited high electrocatalytic sensitivity and selectivity towards the oxidation of DA; $I_{\mathrm{p}, \mathrm{a}}$ of DA was increased by a factor of 8 , and the overlapped oxidation potentials of AA and DA appeared around $+512 \mathrm{mV}$ on the bare GCE, were separated by $150 \mathrm{mV}$, and shifted to more facile direction, +170 and $+320 \mathrm{mV}$ versus $\mathrm{Ag} / \mathrm{AgCl}$, respectively. This behavior allowed elimination of the interference effects of several biological species, so that $5 \mathrm{mM}$ of glucose, $4.5 \mathrm{mM}$ of fructose, $0.58 \mathrm{mM}$ of sucrose, $0.28 \mathrm{mM}$ of cystine, $0.25 \mathrm{mM}$ of ascorbic acid, $79.6 \mathrm{mM}$ of cysteine, and 49.7 of uric acid or urea did not interfere significantly. Therefore, the proposed method was successfully used for quantitative determination of DA in industrial (injection medicine) and biological fluids (blood plasma) real samples with satisfactory results.

\section{Acknowledgments}

The authors acknowledge the University of Isfahan providing research facilities for this work. Special thanks are due to Dr. Naser Ekramian's Medical Diagnostic Lab (Isfahan, Najafabad, I.R. Iran) for free sharing his Lab facilities, collection of blood samples, and preparation of blood plasma.

\section{References}

[1] R. K. Shervedani, S. M. Siadat-Barzoki, and M. Bagherzadeh, "Electrochemical characterization of gold 6-amino-2-mercaptobenzothiazole self-assembled monolayer for dopamine detection in pharmaceutical samples," Electroanalysis, vol. 22, no. 9, pp. 969-977, 2010.

[2] R. N. Goyal and S. P. Singh, "Simultaneous voltammetric determination of dopamine and adenosine using a single walled carbon nanotube-modified glassy carbon electrode," Carbon, vol. 46, no. 12, pp. 1556-1562, 2008.

[3] J. Argüello, V. L. Leidens, H. A. Magosso, R. R. Ramos, and Y. Gushikem, "Simultaneous voltammetric determination of ascorbic acid, dopamine and uric acid by methylene blue adsorbed on a phosphorylated zirconia-silica composite electrode," Electrochimica Acta, vol. 54, no. 2, pp. 560-565, 2008.

[4] H. M. Huang and C. H. Lin, "Methanol plug assisted sweeping-micellar electrokinetic chromatography for the determination of dopamine in urine by violet light emitting diode-induced fluorescence detection," Journal of Chromatography $B$, vol. 816, no. 1-2, pp. 113-119, 2005.

[5] M. Shou, C. R. Ferrario, K. N. Schultz, T. E. Robinson, and R. T. Kennedy, "Monitoring dopamine in vivo by microdialysis sampling and on-line CE-laser-induced fluorescence," Analytical Chemistry, vol. 78, no. 19, pp. 6717-6725, 2006.

[6] T. Madrakian, A. Afkhami, L. Khalafi, and M. Mohammadnejad, "Spectrophotometric determination of catecholamines based on their oxidation reaction followed by coupling with 4aminobenzoic acid," Journal of the Brazilian Chemical Society, vol. 17, no. 7, pp. 1259-1265, 2006.

[7] X. Cao, L. Luo, Y. Ding, X. Zou, and R. Bian, "Electrochemical methods for simultaneous determination of dopamine and ascorbic acid using cetylpyridine bromide/chitosan composite film-modified glassy carbon electrode," Sensors and Actuators B, vol. 129, no. 2, pp. 941-946, 2008.

[8] X. Xu, S. Zhang, H. Chen, and J. Kong, "Integration of electrochemistry in micro-total analysis systems for biochemical assays: recent developments," Talanta, vol. 80, no. 1, pp. 8-18, 2009.

[9] S. Shahrokhian and H. R. Zare-Mehrjardi, "Cobalt salophenmodified carbon-paste electrode incorporating a cationic surfactant for simultaneous voltammetric detection of ascorbic acid and dopamine," Sensors and Actuators B, vol. 121, no. 2, pp. 530-537, 2007.

[10] E. Shams, A. R. Babaei, A. R. Taheri, and M. Kooshki, "Voltammetric determination of dopamine at a zirconium phosphated silica gel modified carbon paste electrode," Bioelectrochemistry, vol. 75, no. 2, pp. 83-88, 2009.

[11] Q. Sheng, H. Yu, and J. Zheng, "Sol-gel derived terbium hexacyanoferrate modified carbon ceramic electrode: electrochemical behavior and its electrocatalytical oxidation of ascorbic acid," Journal of Electroanalytical Chemistry, vol. 606, no. 1, pp. 39-46, 2007.

[12] M. D. Rubianes and G. A. Rivas, "Highly selective dopamine quantification using a glassy carbon electrode modified with a melanin-type polymer," Analytica Chimica Acta, vol. 440, no. 2, pp. 99-108, 2001.

[13] A. Salimi, E. Sharifi, A. Noorbakhsh, and S. Soltanian, "Immobilization of glucose oxidase on electrodeposited nickel oxide 
nanoparticles: direct electron transfer and electrocatalytic activity," Biosensors and Bioelectronics, vol. 22, no. 12, pp. 3146-3153, 2007.

[14] R. K. Shervedani and M. Bagherzadeh, "Electrochemical characterization of in situ functionalized gold cysteamine selfassembled monolayer with 4-formylphenylboronic acid for detection of dopamine," Electroanalysis, vol. 20, no. 5, pp. 550 $557,2008$.

[15] R. K. Shervedani, M. Bagherzadeh, and S. A. Mozaffari, "Determination of dopamine in the presence of high concentration of ascorbic acid by using gold cysteamine selfassembled monolayers as a nanosensor," Sensors and Actuators $B$, vol. 115, no. 2, pp. 614-621, 2006.

[16] Z. Xun, C. Cai, W. Xing, and T. Lu, "Electrocatalytic oxidation of dopamine at a cobalt hexacyanoferrate modified glassy carbon electrode prepared by a new method," Journal of Electroanalytical Chemistry, vol. 545, pp. 19-27, 2003.

[17] S. M. Chen, M. F. Lu, and K. C. Lin, "Preparation and characterization of ruthenium oxide/hexacyanoferrate and ruthenium hexacyanoferrate mixed films and their electrocatalytic properties," Journal of Electroanalytical Chemistry, vol. 579, no. 1, pp. 163-174, 2005.

[18] T. R. L. C. Paixão and M. Bertotti, "Electrocatalytic oxidation of deoxyguanosine on a glassy carbon electrode modified with a ruthenium oxide hexacyanoferrate film," Electrochimica Acta, vol. 52, no. 5, pp. 2181-2188, 2007.

[19] T. R. L. C. Paixão and M. Bertotti, "Studies on the kinetics of ascorbate oxidation at a ruthenium oxide hexacyanoferrate modified electrode towards the detection at microenvironments," Electrochemistry Communications, vol. 10, no. 8, pp. 1180-1183, 2008.

[20] T. R. L. C. Paixão and M. Bertotti, "FIA determination of ascorbic acid at low potential using a ruthenium oxide hexacyanoferrate modified carbon electrode," Journal of Pharmaceutical and Biomedical Analysis, vol. 46, no. 3, pp. 528-533, 2008.

[21] T. R. L. C. Paixão and M. Bertotti, "Ruthenium oxide hexacyanoferrate modified electrode for hydrogen peroxide detection," Electroanalysis, vol. 20, no. 15, pp. 1671-1677, 2008.

[22] E. Barsoukov and J. R. Macdonald, Impedance Spectroscopy, Theory, Experiment and Applications, Wiley, New York, NY, USA, 2nd edition, 2005.

[23] T. M. Nahir and E. F. Bowden, "Measurement of the rate of adsorption of electroactive cytochrome $\mathrm{c}$ to modified gold electrodes by electrochemical impedance spectroscopy," Langmuir, vol. 18, no. 13, pp. 5283-5286, 2002.

[24] D. Lelievre, V. Plichon, and E. Laviron, "Ac polarography and faradaic impedance of strongly adsorbed electroactive species. Part IV. Experimental study of the faradaic impedance of the redox systems benzo(c)cinnoline-dihydrobenzo(c) cinnoline," Journal of Electroanalytical Chemistry, vol. 112, no. 1, pp. 137145,1980 .

[25] R. K. Shervedani and M. Bagherzadeh, "Hydroxamation of gold surface via in-situ layer-by-layer functionalization of cysteamine self-assembled monolayer: preparation and electrochemical characterization," Electrochimica Acta, vol. 53, no. 22, pp. 6293-6303, 2008.

[26] R. K. Shervedani, A. H. Mehrjardi, and N. Zamiri, "A novel method for glucose determination based on electrochemical impedance spectroscopy using glucose oxidase self-assembled biosensor," Bioelectrochemistry, vol. 69, no. 2, pp. 201-208, 2006.

[27] R. K. Shervedani and A. R. Madram, "Kinetics of hydrogen evolution reaction on nanocrystalline electrodeposited Ni62Fe35C3 cathode in alkaline solution by electrochemical impedance spectroscopy," Electrochimica Acta, vol. 53, no. 2, pp. 426-433, 2007.

[28] R. K. Shervedani and S. A. Mozaffari, "Impedimetric sensing of uranyl ion based on phosphate functionalized cysteamine self-assembled monolayers," Analytica Chimica Acta, vol. 562, no. 2, pp. 223-228, 2006.

[29] A. Lasia, R. E. White, and B. E. Conway, "Electrochemical impedance spectroscopy and its applications," in Modern Aspects of Electrochemistry, J. O'M. Bockris, Ed., vol. 32, chapter 2, pp. 143-248, Plenum Press, New York, NY, USA, 1999.

[30] S. Yuan, W. Chen, and S. Hu, "Fabrication of $\mathrm{TiO}_{2}$ nanoparticles/surfactant polymer complex film on glassy carbon electrode and its application to sensing trace dopamine," Materials Science and Engineering C, vol. 25, no. 4, pp. 479485, 2005.

[31] R. Jurczakowski, C. Hitz, and A. Lasia, "Impedance of porous gold electrodes in the presence of electroactive species," Journal of Electroanalytical Chemistry, vol. 582, no. 1-2, pp. 8596, 2005.

[32] M. Senda and P. Delahay, "Electrode processes with specific or non-specific adsorption: faradaic impedance and rectification," Journal of Physical Chemistry, vol. 65, no. 9, pp. 1580$1588,1961$.

[33] H. D. Yoo, J. H. Jang, B. H. Ka, C. K. Rhee, and S. M. $\mathrm{Oh}$, "Impedance analysis for hydrogen adsorption pseudocapacitance and Electrochemically active surface area of $\mathrm{Pt}$ electrode," Langmuir, vol. 25, no. 19, pp. 11947-11954, 2009.

[34] K. W. Nam and K. B. Kim, "A study of the preparation of NiOx electrode via electrochemical route for supercapacitor applications and their charge storage mechanism," Journal of the Electrochemical Society, vol. 149, no. 3, pp. A346-A354, 2002.

[35] K. W. Nam, K. H. Kim, E. S. Lee, W. S. Yoon, X. Q. Yang, and K. B. Kim, "Pseudocapacitive properties of electrochemically prepared nickel oxides on 3-dimensional carbon nanotube film substrates," Journal of Power Sources, vol. 182, no. 2, pp. 642-652, 2008.

[36] B. E. Conway, “Transition from 'supercapacitor' to 'battery' behavior in electrochemical energy storage," Journal of the Electrochemical Society, vol. 138, no. 6, pp. 1539-1548, 1991.

[37] Z. Liu, X. Y. Ling, X. Su, and J. Y. Lee, "Carbon-supported $\mathrm{Pt}$ and PtRu nanoparticles as catalysts for a direct methanol fuel cell," Journal of Physical Chemistry B, vol. 108, no. 24, pp. 8234-8240, 2004.

[38] J. Huang, Y. Liu, H. Hou, and T. You, "Simultaneous electrochemical determination of dopamine, uric acid and ascorbic acid using palladium nanoparticle-loaded carbon nanofibers modified electrode," Biosensors and Bioelectronics, vol. 24, no. 4, pp. 632-637, 2008.

[39] B. N. Liu, H. Yuan, and Y. Zhang, "Impedance of Alsubstituted $\alpha$-nickel hydroxide electrodes," International Journal of Hydrogen Energy, vol. 29, no. 5, pp. 453-458, 2004. 
[40] S. Motupally, C. C. Streinz, and J. W. Weidner, "Proton diffusion in nickel hydroxide films measurement of the diffusion coefficient as a function of state of charge," Journal of the Electrochemical Society, vol. 142, no. 5, pp. 1401-1408, 1995.

[41] F. C. Moraes, M. F. Cabral, S. A. S. Machado, and L. H. Mascaro, "Electrocatalytic behavior of glassy carbon electrodes modified with multiwalled carbon nanotubes and cobalt phthalocyanine for selective analysis of dopamine in presence of ascorbic acid," Electroanalysis, vol. 20, no. 8, pp. 851-857, 2008. 


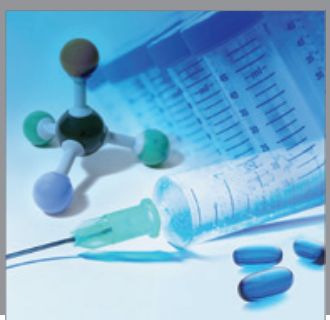

International Journal of

Medicinal Chemistry

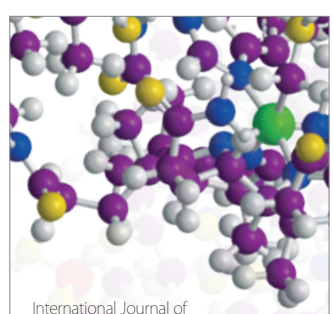

Carbohydrate Chemistry

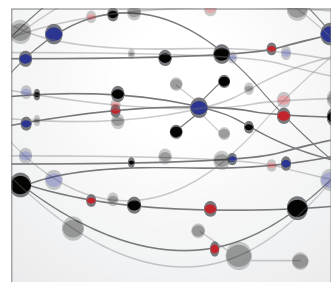

The Scientific World Journal
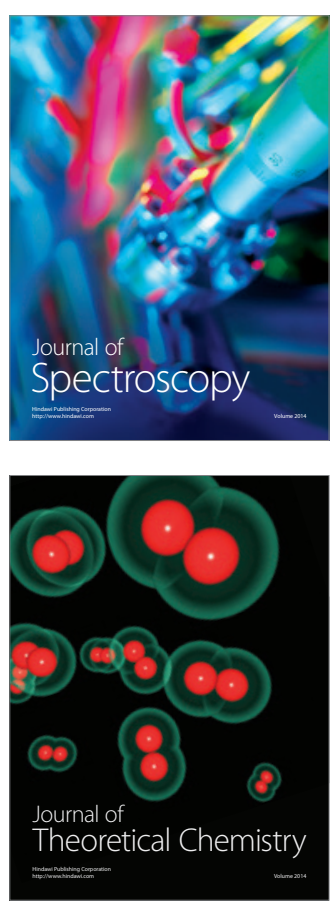
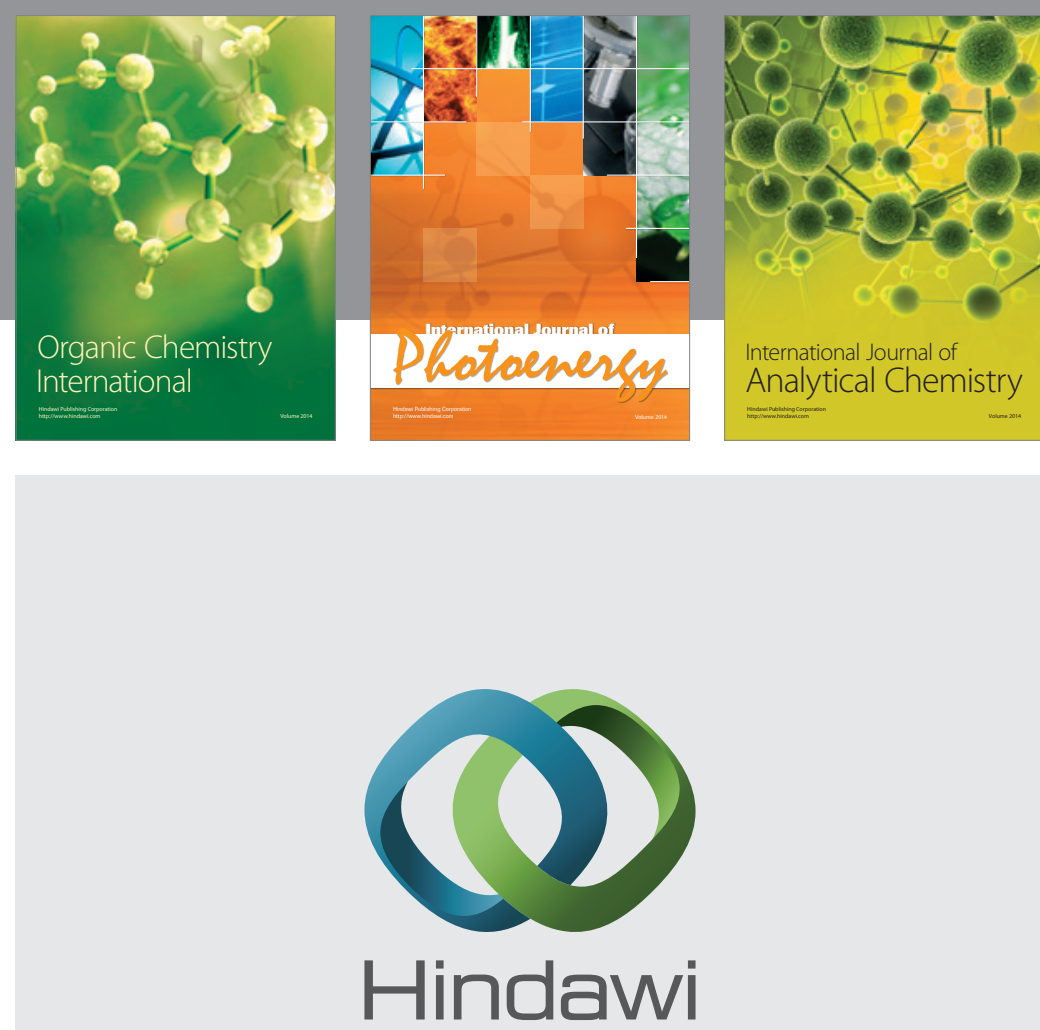

Submit your manuscripts at

http://www.hindawi.com
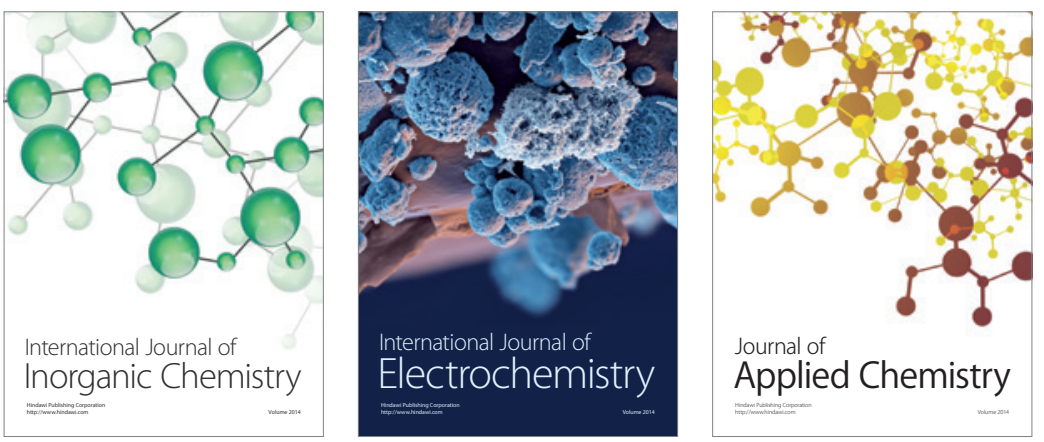

Journal of

Applied Chemistry
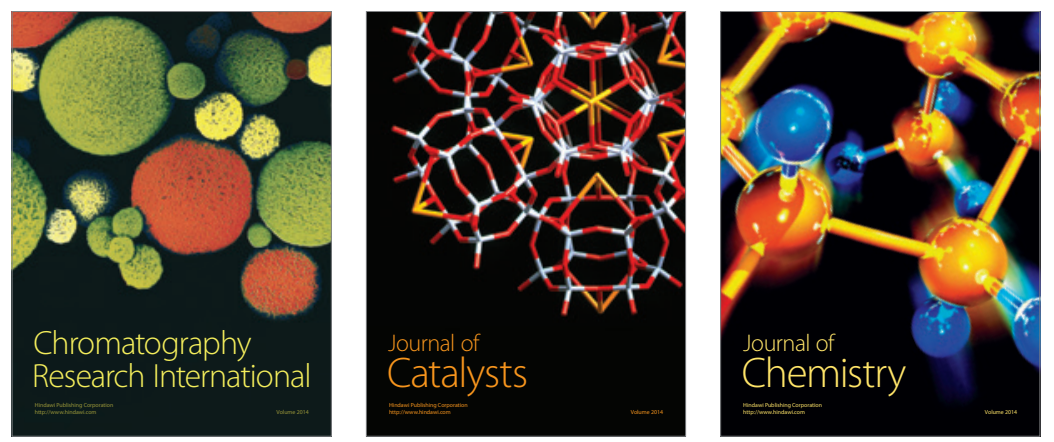
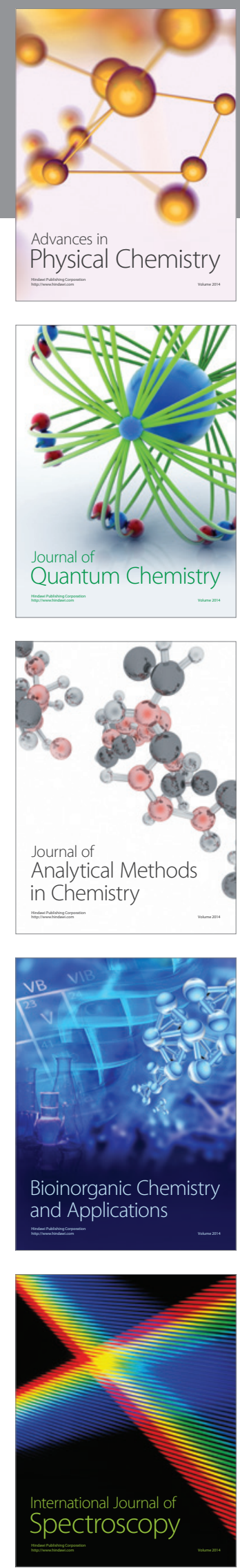